\title{
DIE EVANGELIE EN DIE KULTUUR
}

C W H BOSHOFF

Inleiding: Die belangrikheid van die kultuur as lewensruimte van die mens, ook die christenmens het meteens ontplof.

In Mei 1984 het in Rome die sogenaamde Riano-konsultasie oor Evangelie en Kultuur plaasgevind. Die byeenkoms is deur die Kommissie vir Wêreldsending en Evangelisasie van die Wêreldraad van Kerke en deur die Sekretariaat vir Eenheid van die Rooms Katolieke Kerk byeengeroep.

Die Vancouver byeenkoms van die WRK wat die ondersoek na die verhouding Evangelie en kultuur in 1983 beklemtoon het, verklaar o.a.: "Die vraag na die aard van die verhouding tussen Evangelie en kultuur hou ons al 'n geruime tyd besig, maar kultuur as punt van bespreking is veral om die volgende redes opnuut op die tafel: Eerstens het ons tot 'n dieper begrip van die betekenis en funksie van kultuur en sy verskeidenheid gekom; tweedens tot 'n beter verstaan van die wyses waarop die Evangelie met kultuur in wisselwerking kom, en derdens tot ' $n$ helderder realisering van die probleme wat veroorsaak is deur die verwaarlosing en afskakeling van die ontvangende kulture tydens die westerse sendingera wat dikwels met westerse kolonialisme saamgeval het."

Lees hiermee saam die oortuigende inleiding van John Scott tot die versamelwerk Down to Earth, studies in Christianity and Culture en dan die steeds belangrike proefskrif van N J Smith, Elkeen in sy eie taal, Die planting van afsonderlike kerke vir nie-Blanke volksgroepe deur die Nederduitse Gereformeerde Kerk in Suid-Afrika. Naas etlike ander publikasies in resente tydskrifte kom twee belangrike tydskrifte uit met Evangelie en kultuur as temanommers, nl. Wêre/d en Zending en Zeitschrift für Mission. ${ }^{11}$

Vroeëre uitsprake in hierdie verband verneem ons reeds by $\mathrm{J}$ Blauw wat in 1958 skryf: "Onlangs sprak een Afrikaan de betekenisvolle woorden: wij willen afrikanen zijn, geen zwarte europeanen. Daarmede gaf hij uitdrukking aan een gevoel van onbehagen, dat bij velen leeft. Zowel de kerk als de staat is in de meeste jonge zelfstandige of bijna zelfstandige staten gevormd naar europees model." 2)

Hy haal Rev W J Stone aan wat verklaar dat daar niks in die Europese agtergrond is wat ooreenkom met die Afrikaanse geesteswêreld nie. Inteendeel, óns geeste is bepaal deur 'n onuitgesproke geloof in ' $n$ verstandelike, wetenskaplike verklaring van álles wat gebeur. Daarom gebeur dit dat die meeste sendelinge die Afrikaanse geestes- 
wêreld met onbegrip, veragting en selfs boosheid bejeen. Die Afrikaanse predikant is egter ten voile oortuig van die werklikheid van daardie wêreld. Maar hy weet nie wat hy in Christus naam daarmee moet aanvang nie. Dikwels durf hy nie die sendeling daaroor raadpleeg nie - uit vrees enersyds vir die wraak van die geeste, maar andersyds vir die reaksie wat hy van die sendeling sal ontvang. Daarom laat hy dit so - en die geesteswêreld is springlewendig en beheers die Afrikaanse samelewing en homself dikwels daarby ingesluit. Die onafhanklike kerke wat ' $n$ Afrika-verskynsel geword het, is waarskynlik een van die belangrikste gevolge hiervan. ${ }^{3)}$

'n Amerikaanse sendeling van resente tyd kom met die getuienis van sy ontnugtering op die sendingveld in Afrika. Hy noem sy boek The Naked Gospel: Stamping out Ready to Wear Christianity (1981) en verklaar dat sy toerusting vir die sending, waarmee hy geesdriftig na Afrika vertrek het, was vier jaar teologie en nog ses jaar verdere studie. Sy ontnugtering was om uit te vind dat dít nie die Evangelie was nie; die Evangelie is veel eenvoudiger maar ook veel dieper. Wat die mense verwerp het, was nie die Christelike geloof nie, maar ons voorstelling daarvan. Toe het hy begin met die proses om alles wat geleerd was, alles wat Westers, Europees, blank, Amerikaans was, af te skil en te soek na die "naakte Evangelie." Daarmee word die diepste en fundamentele substansie van die Christelike boodskap bedoel. Sy belangrike slotsom waartoe hy kom is: "I don't think we really discovered it but we are searching for it. The reason I say I don't think we discovered it is because I think we won't really discover it until we present it to every culture in the world and then have those cultures play it back to us. Then I think we'll know the gospel." 4 )

Treffend is die getuienis van die Roomse biskop van Lusaka wat in 1983 deur sy kerk op grond van sekere praktyke waaraan hy hom skuldig gemaak het, teruggeroep is. In 'n koerantonderhoud verklaar hy: "The attitude of Africa is not so much to do away with all that is Western, but to tell Europe that we also have ... values, an inheritance that the Lord has given us. Anyone who is going to misinterpret the search for identity and authenticity of the Africans as racism, as discriminatory, is just being prejudiced." ${ }^{5}$ )

In sy inleidende referaat tot die Riano-konsultasie het Julius Lipner die volgende belangrike standpunt ingeneem: "I used to believe that the ideal of Christian mission would be fulfilled if there were maximum uniformity in belief, practice and worship with the minimum of ethnic diversity. I now realize that this is not only humanly impossible, for obvious reasons, but theologically undesirable because such an ideal would contradict the nature of Gods mission to us in Jesus as it is revealed in 
scripture. This is a mission that respects our human way of being, in its freedom and diversity. I believe, in fact, that for the gospel to stay alive, challenging and transforming, it is necessary that it find expression in cultural diversity ..."6).

\section{Wat is Kultuur?}

Waar daar nou reeds soveel oor die noodsaaklikheid van die erkenning van kultuur gesê is, moet daar 'n poging aangewend word om hierdie moeilike begrip te definieer. By die Vancouver-vergadering van die WRK is die volgende definisie aan die hand gedoen: "Kultuur is dit wat die gemeenskap bymekaar hou en wat daaraan 'n gemeenskaplike raamwerk van begrip gee. Dit word bewaar in taal, gedagtepatrone, lewenswyse, benaderings, simbole en voorveronderstellings en word geniet in kuns, musiek, drama, literatuur en dies meer. Dit vorm die kollektiewe herinnering van die volk en die gemeenskaplike erfenis wat aan die geslagte wat nog kom, oorhandig sal word." ")

Dat ons hier met 'n breë, omvattende definisie te doen het, word toegegee, maar dat alles ook nog nie gesê is nie is ook duidelik. Dit moet veral in gedagte gehou word dat elke volk, hoewel sommige in 'n meerdere en andere in ' $n$ mindere mate, met twee vorme van kultuur te doen het. Enersyds is daar die universele kultuur wat die eiendom en erfenis van die hele mensheid is. In 'n kleiner wordende wêreld met al meer en beter kommunikasiemedia word die aandeel van volke aan die universele kultuur al groter. Daarnaas is daar egter ook individuele of eiesoortige kultuur wat elke volk se eie besit is. Daaraan word volke geken en onderskei hulle hulleself van ander volke. Daarmee verryk elke volk ook die besit van die totale mensheid en sou dit ' $n$ verlies en ' $n$ verarming wees as die eiesoortige kultuur in geheel ter wille van ' $n$ universele kultuur prysgegee word. Eintlik is dit onmoontlik en teen die natuur omdat elke volk geneig is om hardnekkig sy kultuur-eie te bewaar. Feit is egter dat daar eenheidspredikers en egalitariste is wat ' $n$ "great society" met een mensheid en een kultuur as die hoogste ideaal sien. Dit is hierteenoor dat die ontdekking van die waarde van elke volk se eie kultuur in die nuwe benadering van die Evangelie en kultuur-konsultasie van besondere belang is.

\section{Wat is Evangelie?}

In die verhouding Evangelie en kultuur is die definisie van kultuur belangrik; daar sal egter ook gevra moet word wat onder die Evangelie bedoel word. Die Evangelie, soos dit in die Nuwe Testament en in sy 
fundering in die Ou Testament tot ons kom, is natuurlik self kultureel verpak. Dit praat in die taal en die idioom van die tyd. Die leefwêreld, die raamwerk van idees, die gebrek aan sekere wetenskaplike feitekennis ens., word onbeskaamd in die Evangelie erken. "We may well ask if it is possible to get behind those 'cultures' to some de-cul-turized kernel of truth and reality. Even more, is not the very nature of God's incarnation in Jesus Christ, in a peculiar time and place and people, an indication that God intends to be known in and through culture, not apart from it? The search for a 'pure gospel' may well lead us to a more intensive study of scripture so that we may plumb the depths of God's will and purposes ever more fully, but in fact the search may be doomed to failure for there may not be any 'pure gospel', and even if such exists we are bound to understand it in the human cultural categories of our own minds, language and perceptions which themselves are culturally defined", is die opmerking van die "Editorial" van die IRM in dié verband. ${ }^{8 \text { ) }}$

Die Evangelie van Christus het nie in 'n kulturele vakuum gekom nie en word ook in die sendingvelde nie in kulturele vakuums oorgedra nie. Vandaar die belang van voortgesette navorsing en oorweging in die verband. Dat ander godsdienste ook oomblikke van aangrypende belewing van hulle verhouding tot God beleef, word met eerbied en piëteit erken. Mens dink aan 'n gebed van 'n vroue-Moslem, vrou Rabi'a van Bosra wat deur J H Bavinck aangeteken is: " $\mathrm{O}$, my Lord, the stars are shining and the eyes of men are closed, and kings have shut their doors, and every lover is alone with his beloved, and here am I alone with Thee. 0 , my Lord, if I worship Thee from fear of hell, burn me in hell, and if I worship Thee in hope of paradise, exclude me thence, but if I worship Thee for Thine own sake, then withhold not from me Thine eternal beauty." ${ }^{\prime \prime \prime}$

Daar is meer sulke voorbeelde te vind en dit pas ons as Christene om nie ons oë te sluit vir daardie vonke van waarheid en toewyding in die lewens van aanhangers van ander godsdienste nie. Huigel kan dit nie wees nie. Dat dit deel van die kultuur van die mense is aan wie die Evangelie gebring moet word, lê voor die hand. Daarom verdiep die Evangelie-kultuur vraagstuk juis wanneer daar met die religieuse wortels van die kultuur van sulke volke erns gemaak word ...

En al sou ons ook die sleutel van Rom. 3:23, "Almal het gesondig en is ver van God af, maar hulle word sonder dat hulle dit verdien, op grond van sy genade vrygespreek vanweë die verlossing deur Jesus Christus," aanwend, dan besef ons ook dat waar die Evangelie nou gebring word, is dit nie in 'n kulturele vakuum nie. Wie geleer het om in ootmoed voor die "onbekende God" te buig, sal met groter toewyding aan God wat Hom in Christus geopenbaar het, sy nuwe lewe inrig. 
Die vraag oor kontinuïteit of diskontinuïteit tussen die valse godsdiens en ware geloof word dan op 'n hoër vlak opgeklaar: "Almal het gesondig en is ver van God af" - maar as hulle sonder dat hulle dit verdien, gered is, sal "die mense die skatte en die rykdom van die nasies" in die heilige stad inbring (Openb. 21:26).

\section{'n Roep om die bewaring van die kultuur}

In 1980 skryf kardinaal Victor Razafimahatratra van Madagaskar 'n herderlike brief oor die bydrae van die Christen in die maatskappy. Aan die einde verklaar hy: "Heelwat van die probleme wat die gevolg is van die keuse vir 'n produktivistiese beskawing - 'n keuse wat ons land met die geïndustrialiseerde lande deel, - sou ons gespaar kon bly as rekening gehou is met bepaalde kulturele waardes wat karakteristiek is van ons nasionale identiteit. Ons lewensbeskouing gee voorrang aan harmonie in die verhouding met andere en met die natuur. Wanneer ons hierdie wesenlike trek van ons beskawing nie eerbiedig nie, sal ons of ons identiteit vernietig in die naam van ' $n$ onmenslike vooruitgang, of sal alle toekomsprojekte misluk deur die gehegtheid van die volk aan sy eie waardes."'10)

Renato Constantino kom in verset teen 'n sintetiese kultuur wat die kulturele erfgoed in die Derde Wêreld bedreig. Die stelling word gemaak: "Die mens word gebore in 'n bepaalde kultuur wat histories gegroei het. Hy neem simbole, tradisies, begrippe, waardebepalinge in hom op, wat hom met die samelewing in verbinding bring, soos die samelewing die verbindende faktor is tussen homself en sy materiële omgewing. In 'n groot deel van die Derde Wêreld is hierdie kulturele erfgoed teenswoordig in gevaar. Ontwikkelingslande kan op kulturele terrein nouliks staande bly teenoor die transnasionaal geworde kommunikasiemiddele. Inheemse kulture word in hulle bestaan bedreig deur ingrypende veranderings, deurdat die westerse kultuur aangebied word as die kultuur wat elke staat wat aan die moderne tyd wil meedoen, sy eie moet maak." "Massakultuur" sê hy, het anti-kultuur geword. "Die term massakultuur is ' $n$ ontkenning van egte kultuur, omdat dit volgens westerse verbruikerspatroon aangepas word om vir soveel moontlik mense bruikbaar te wees (die grootste gemene deler)". Hierdie sintetiese massakultuur moet duidelik onderskei word van die kultuur van die volk. Laasgenoemde kom uit die mense self voort en het te doen met hulle eie node en toekomsverwagtings. ${ }^{11}$

Die klag word uitgespreek dat die ekonomie die aard van 'n natuurverskynsel gekry het, dit modelleer mense en kulture met dwingende mag. Op aggressiewe wyse word die verskeidenheid van plaaslike kul- 
ture vernietig en vervang deur 'n wêreldwye sintetiese kultuur. Bedrieglike terminologieë soos vooruitgang of ontwikkeling moet die ware karakter van wat voor die oë afspeel, bedek.

Op ' $n$ Urban-Rural konferensie in 1978 in Asië word onomwonde verklaar: "In Asië het 'ontwikkeling' vir die plaaslike bevolking en vir ander minderhede geen sin nie. Ontwikkeling is nie ' $n$ woord van ons nie. Ons aanvaar geen ontwikkeling soos dit deur die heersende groepe opgelê word nie. Ons begeer dit nie, want dit vervreem en disintegreer ons volk. Dit vernietig menslike waardes wat vir ons baie belangrik is. Die materialistiese visie op die lewe wat in die proses oorheers, lei tot selfvernietiging. Dit wil ons nie. Ons wil erkenning. Ons wil dat ons manier van lewe, ons kyk op land en familie, ons tale en kulture erken word."12)

Dieselfde benadering vind ons by skrywers in die Zeitschrift für Mission. Hier verklaar die bekende John S Mbiti: "... das vom Tag der Auferstehung an das Evangelium eine Kultur nach der andere durchwandert. Keine Kultur kann das Evangelium für sich beanspruchen, da es allgemeines Eigentum ist. Aber das Evangelium braucht die Kultur, weil es nicht in einem Vakuum verkündigt werden kann, und das Volk reagiert negativ oder positiv in seinem eigenen Kulturellen Milieu. Es ist die Kultur die ihnen hilft, das Evangelium zu verstehen zu artikulieren, zu kommunizierung und zu feieren. Wenn das Evangelium eine vorhandene Kultur erreicht, wenn dort eine menschliche Antwort im Glauben ist, dann entwickelt sich das Christentum in diesem Kontext, als ein Ergebnis sowohl des Evangeliums von Jesus Christus und auch der Kultur verschiedenen Formen oder Ausdrücken von Christentum in aller Welt auferkennen." 13 )

Omdat die Evangelie die kultuur gebruik, het dit ook ' $n$ invloed op die kultuur, sê hy. Die Evangelie moet die kultuur aanneem en red; dit moet kulturele demone verdryf en kulturele waardes heilig sodat die Evangelie en die kultuur vir mekaar tot wedersydse nut kan wees. Hierdie soort van verbinding het intussen in die gemeenskappe van Afrika, Asië en die Stille Oseaan waar die christelike geloof in die laaste tweehonderd jaar gevestig is, sigbaar geword. Die vroeëre standpunte van sendelinge in hierdie gebiede was dat die inwoners nie gered kan word as hulle nie hulle kultuur in westerse gestaltes kon omskep nie. Dit was wat die Joods-christene die gelowiges uit die heidendom ook wou oplê (vgl. Hand. 15), maar die Gees van God het by die Jerusalemkonsilie die leiding gegee dat gelowiges uit die heidendom nie met Joodse kultuur belas moes word nie.

Hy sluit: "Nur wenn das Evangelium in den kulturellen Tiefen der südlichen Regionen fest verwurzelt ist, werden wir zu den Punkt in der christlichen Geschichte Kommen, an dem alle Völker dieser Welt voll an 
den Reichtümmern des Evangeliums und ihrer Kulturen teilhaben werden."14)

Menezes Limbindo bevestig dit as hy sê: "Heutzutage versuchen wir, dieses Vakuum zu füllen. Wir versuchen als Afrikaner mit unserer afrikanischen Identität und Kultur das Evangelium zu erleben." ${ }^{15}$ )

\section{Evangelie en Kultuur}

Dit het nou hoog tyd geword dat ons in die lig van die behoeftes soos hierbo omskrywe 'n poging aanwend om aan te toon hoe die kultuur deur die Evangelie gerespekteer, maar ook in besit geneem word.

1. Van kultuur moet eerstens sy dinamiese karakter erken word. Geen kultuur is stagnant, onveranderlik of onbeweeglik nie. Omdat die kuituur die lewe van ' $n$ bepaalde gemeenskap beliggaam, is stagnasie solank die gemeenskap lewe, onmoontlik. Daar sal dus voortdurend ook verandering in die kultuur plaasvind.

2. Verder moet van kultuur aangemerk word dat dit omvattend is, dit sluit alles in wat 'n kultuurgemeenskap doen, geërf het, self skep en aan die volgende geslag oordra. Daarom moet dit ook in ag geneem word dat kultuur konkreet én ook geestelik is. Dit is die skepping van die hand en van die gees. Die musiekinstrument is net sowel kultuurskepping as die melodie wat daarop gespeel word.

3. Ewe belangrik is egter die feit dat kultuur ook eiesoortig is. Trouens, dit is die punt waarom die hele argument wentel. Die verskeidenheid van volke is 'n kultuurverskeidenheid, daardeur word elke volk se identiteit bepaal en al sou kulture ook kontekstueel verander of aanpas, die cachet van eiesoortigheid word gehandhaaf. word:

Om dit in ' $n$ kultuurmodel voor te stel, kan dit soos volg gedoen $\begin{array}{llcrr} & \text { KULTUUR } & & \\ \text { Histories gebonde } & - & \text { DINAMIES } & - & \text { Toekomsgerig } \\ \text { Konkreet } & - & \text { OMVATTEND } & - & \text { Geestelik } \\ \text { Identiteit } & - & \text { EIESOORTIG } & - & \text { Kontekstueel }\end{array}$

A GESTALTES VAN KULTUUR

GEINSTITUSIONALISEERD GEORGANISEERD Gesin 
Opvoeding

Godsdiens

Staat
Belangeorganisasies

Liefdadigheidsorganisasies

Kultuurorganisasies

Kunsverenigings

Sportklubs
Kuns

Handwerk

Lees

B DETERMINERENDE FAKTORE VAN KULTUUR Waardes

Norme

C DIEPTESTRUKTURE VAN KULTUUR

Die lewens- en wêreldbeskouing

God Mens

Wêreld

Lewe

Dood

Volgens hierdie model omvat die totale kultuur in die eerste plek Die Gestaltes van Kultuur. Hulle is geïnstitusionaliseerd, georganiseerd en spontaan.

1. Onder Geïnstitusionaliseerde Gestaltes onderskei ons:

1.1 Die Gesin met verlowing, huwelik, geboorte, inisiasie, verhoudinge ens., dit wat rondom die gesin in die kultuurgemeenskap eiesoortig beoefen word.

1.2 Die Onderwys, die skool of opvoedingsinstellings wat vaste instellings in die verskillende gemeenskappe word. Ook die leerstof en die raamwerk waarbinne dit verpak word.

1.3 Die Godsdiens. Al sou die godsdiens en die geloof as deel van die dieptestrukture beskou word, is die uitdrukking daarvan in kerkgang, liturgie en ritueel deel van die vasgelegde kultuur.

1.4 Die Staat, staatsvorm, regeringsinstelling, monargie, demokrasie, gesag, regspraak, ordes en simbole en alles wat daarmee saamhang, is kultureel gebonde en gee uitdrukking van 'n kultuurgemeenskap se eiesoortigheid.

Hierdie kultuurgestaltes is dieper gestruktureer as die volgende, $\mathrm{nl}$ :

2. Die Georganiseerde Gestaltes van kultuur. Georganiseerde kultuurgestaltes het ook vaste strukture maar tog minder as die eerste groep. Hier geld veral arbeid en arbeidsorganisasie, belangegroepe, liefdadigheidsorganisasies, sportklubs, kunsverenigings, jeug, vroue-of gewoon kultuurorganisasies. Dit wil sê al daardie soort aktiwiteite wat 'n kultuurgemeenskap op georganiseerde wyse onderneem. Alhoewel 
sulke organisasies nie altyd eksklusief is nie, dra dit tog meesal 'n eiesoortige karakter veral vanweë die taal en ander voorkeure waaraan 'n spesifieke gemeenskap geheg is.

3. Spontane kultuurgestaltes is legio: lees, sing, reis, stories vertel, kuier, sit en brei of vleg, tuinwerk ens. ens. Alles wat mens doen tot eie bevrediging, vervulling of genot.

Die vraag waarom daar aan hierdie gestaltes van kultuur, wat uiteindelik die kultuurgemeenskap karakteriseer, eiesoortigheid kleef, word deur die tweede vlak, wat ons Determinerende Faktore van kultuur noem, bepaal. Saamgevat, is dit die waardes en die norme van die gemeenskap. Onder waardes verstaan ons die dinge wat nagestreef word, en onder norme die dinge waarmee gemeet word.

Wat in die huwelik, op die skool, in die kerk of in die staat; in die arbeid of in allerlei organisasies of in die spontane aktiwiteite plaasvind of gebeur, word bepaal deur die waardes en norme wat meesal, eie aan ' $n$ gemeenskap is. Daardie faktore gee aan 'n kultuurgemeenskap sy cachet.

Maar dadelik moet opgemerk word dat waardes en norme nie op hulleself absoluut is nie, dit staan nie op hulleself nie. Hulle is die resultaat van die gemeenskap se lewens- en wêreldbeskouing - Die dieptestruktuur van 'n gemeenskap.

Dit is voorts treffend om daarop te let dat elke gemeenskap, hoe hoog ontwikkel of hoe primitief ook al, sy lewens- en wêreldbeskouing uit vyf elemente saamstel.

1. Die eerste en deurslaggewende is sy Godsbeskouing. Wie is God, hoe is God, wat doen God, wat is my verhouding tot God?

2. Die mensbeskouing. Wat is die mens, wat is my verhouding tot die medemens, wie is my medemens - net dié wat tot my groep behoort of die hele mensheid?

3. Die wêreld. Vanwaar is die wêreld, wat is die wêreld en wat is my verhouding tot die wêreld?

4. Die beskouing oor die lewe - die herkoms en bestemming daarvan.

5. Die dood.

Uit hierdie vyf elemente word elke kultuurgemeenskap se lewens- 
en wêreldbeskouing opgemaak. Dit bepaal sy waardes en norme en determineer uiteindelik die gestaltes van sy kultuur.

Die lewens- en wêreldbeskouing kan op verskillende maniere getipeer word. Dit kan humanisties, liberalisties, materialisties, primitief, Christelik wees. Die humanisme verlê die klem van die Godsbeskouing na die mensbeskouing en maak sy humaniteit of menslikheid die beslissende faktor. Vir die liberalisme is die vrye mens die deurslaggewende. Vir die Christelike geloof is die Bybelse visie op God, mens, wêreld, lewe en dood die bepalende faktor. God is die Vader van Jesus Christus en ook van my deur sy versoening. Die mens is beelddraer van God en medemens, naaste van mekaar. Die wêreld is deur God geskape, die werkterrein van die mens en nie die versameling van geheimsinnige kragte van hemelmagte en aardse magte wat op mekaar inspeel nie. Die lewe is God se gawe aan die mens, God se tyd, die mens se geleentheid en die dood is vir die Christen die mag van sonde wat gebreek is en daarom van sy skrik en oorwinning beroof is.

'n Bybelse visie op die vyf elemente gee dus 'n baie duidelike stel waardes en norme wat weer onmiskenbaar die gestaltes van die kultuur determineer.

Sou mens dus tot 'n bepaalde volk die Evangelie bring, sal die beginpunt nie wees om met die gestaltes van die kultuur fout te vind en op ander (Christelike) gestaltes aan te dring nie. Mens dink bv. aan poligamie in die huwelik, die doodmaak van tweelinge, magiese praktyke en geestesverering ens. Dit sou selfs nie help om oor die waardes en die norme in gesprek te tree nie.

Die beginpunt en konsentrasie van die Evangelie is op die dieptestrukture, op die vraag: "Wat het jy met God gedoen." Vandaar wentel die Godsvraag hom af op die vraag om die mens as medemens, vandaar na die wêreld, die lewe en die dood. Uit die Bybelse suiwering van die dieptestrukture word nuwe waardes en norme gevorm en hieruit volg eers die verandering van die gestaltes van kultuur in die samelewing.

\section{Eiesoortigheid}

Die gedagte sou nou inderdaad ontstaan dat as die dieptestruktuur met die Woord van God gekonfronteer is en die Evangelie met die lewens- en wêreldbeskouing gehandel het, dan moet die waardes en die norme tog eenders wees en die gestaltes van die kultuur uiteindelik identies met almal wat Christene geword het. Dan is die Evangelie die groot gelykmaker, die vernietiger van eiesoortigheid en die skepper van die eenheidsgemeenskap.

Hierin verskyn egter die wonder. Soos wat elke volk sy eie taal het 
en God in soveel tale geprys word, so het God ook die mens gemaak dat sy eie tyd, gebeure en geskiedenis, sy eie land, klimaat en omgewing, sy eie innerlike belewenis, reaksies en houding 'n duisend kultuurgemeenskappe kan skep wat elkeen na Gods Woord luister, elkeen God erken en loof, elkeen deelneem aan die simfonie van die eer van God, sonder dat die een 'n replika van die ander geword het.

Natuurlik beteken dit nie dat slegs 'n bepaalde getal kulture of kultuurgemeenskappe (lees volke) geskep is en dat hulle nooit mag vermeerder en nooit mag verminder nie. Juis die dinamiese karakter weerlê die gedagte. Maar dat die kultuurgemeenskap die reg en die roeping het om sy kultuur te bewaar, te verryk en bo alles te heilig in die lig van die Evangelie, is juis die argument van hierdie gesprek. Volkere, veral uit die Derde Wêreld roep om die erkenning, die bewaring en die eerbiediging van hulle eiesoortige kulture, wanneer hulle die Evangelie as 'n gawe van God aanvaar het, en stry teen die vernietiging daarvan deur oorweldigende mag van kulturele holisme.

Juis dit is die wyse waarop Openbaring 5:9 in vervulling gaan:

"Toe sing hulle 'n nuwe lied:

$U$ is waardig om die boek te neem

en die seëls daarvan oop te maak

omdat $U$ geslag is

en met $u$ bloed mense vir God

losgekoop het

uit elke stam en taal

en volk en nasie."

\section{NOTAS}

1. Vgl. International Review of Mission, Gospel and Culture, Vol LXXIV No. 294 (April 1985), 135; R T Cook and John Stott, (Ed.) Down to Earth. Studies in Christianity and culture, Grand Rapids 1980, vii e.v.; N J Smith, Elkeen in sy eie Taal, Pretoria 1980; Wêreld en Zending. Economie, Cultuur en Evangelie, (1985/4); Zeitschrift für Mission, Evangelium und Kultur, Jahrgang XI 3, (1985).

2. J Blauw, Die andere wereld, Kampen 1958, 58.

3. Ibid., 58 e.v.

4. Lamin Sanneh, "Christian mission in the pluralist milieu, the African Experience", IRM LXXIV No 294 (April 1985), 202, 203.

5. Ibid., 208.

6. Julius Lipner, "Being one, let me be many. Facets of the relationship between the gospel and culture," IRM LXXIV No. 294 (April 1985), 167.

7. "Editorial", IRM LXXIV No 294, 154.

8. A.W., 154.

9. J H Bavinck, The Impact of Christianity on the Non-Christian world, Grand Rapids 1948, 96. 
10. Vgl. die Nederlandse vertaling uit die Frans in Wêreld en Zending, Economie, Cultuur en Evangelie (1985/4), 303.

11. Vgl. Renato Constantino, "Filipijns verzet tegen een synthetische cultuur", Wére/d en Zending (1985/4), 312 e.v.

12. Vgl. "Ten geleide, Economie, Cultuur en Evangelie," Wêreld en Zending (1985/4), 281 e.v.

13. John Mtuti, "'Ein lebendiger Entwicklungsprozess," Zeitschrif für Mission, Jahrgang XI 3 (1985), 140 vv.

14. Ibid., 141.

15. Menezes Limbindo, "Evangelium und Kultuur," Zeitschrift für Mission Jahrgang XI 3 (1985) 